\title{
THE USE OF POLYNOMIAL SHAPE FUNCTION IN THE BUCKLING ANALYSIS OF CCFC RECTANGULAR PLATE
}

\author{
Ezeh, J. C. ${ }^{1}$, Ibearugbulem, O. M. ${ }^{2}$, Nwadike, A.N. ${ }^{3}$, Maduh, U. J. ${ }^{4}$ \\ ${ }^{1}$ Associate Professor, Civil Engineering Department, Federal Unitech Owerri, Imo State, Nigeria, \\ jcezeh2003@yahoo.com \\ ${ }^{2}$ Civil Engineering Department, Federal Unitech Owerri, Imo State, Nigeria, ibeowums@yahoo.co.uk \\ ${ }^{3}$ Civil Engineering Department, Federal Unitech Owerri, Imo State, Nigeria, nwadikeamarachukwu@yahoo.com \\ ${ }^{4}$ Civil Engineering Department, Federal Unitech Owerri, Imo State, Nigeria,ujmaduh@gmail.com
}

\begin{abstract}
The use of polynomial series function in the buckling analysis of a CCFC is presented. The polynomial series shape function was truncated at the fifth orthogonal terms, which satisfied all the boundary conditions of the plate to obtain a peculiar shape function, which was applied in Ritz method. The peculiar shape function is substituted into the total potential energy functional, which was minimized, and the critical buckling load of the plate was obtained. The critical buckling load is a function of a coefficient, " $K$ ". The values of $K$ from earlier and the present studies were compared within the range of aspect ratios from 0.1 to 2.0. A graph of critical buckling load against aspect ratio was plotted. It was discovered that for aspect ratios of 0.4, 0.5 and 1.0, the critical buckling loads coefficients were 26.94, 17.39 and 4.83. It was also observed from the behavior of the graph that as aspect ratio increases from 0.1 to 2.0, the critical buckling load decreases.
\end{abstract}

Keywords: Total Potential Energy Functional, Shape Function, Polynomial Series Shape Function, Critical Buckling load, Boundary Condition, Ritz Method.

\section{NOTATION}

$\mathrm{W}$ is the shape function (deflection function).

$\mathrm{V}$ is the shear force.

$\mu$ is Poisson's ratio

First partial derivative of deflection with respect to $\mathrm{R}$ is: $w^{\prime R}=\frac{\partial w}{\partial R}$.

First partial derivative of deflection with respect to $\mathrm{Q}$ is: $w^{\prime Q}=\frac{\partial w}{\partial Q}$

Second partial derivative of deflection with respect to $\mathrm{R}$ and $\mathrm{Q}$ is: $W^{\prime} R^{\prime} Q=\frac{\partial^{2} w}{\partial R \partial Q}$

Second partial derivative of deflection with respect to $\mathrm{R}$ is: $w^{\prime \prime R}=\frac{\partial^{2} w}{\partial R^{2}}$

Second partial derivative of deflection with respect to $\mathrm{Q}$ is: $w^{\prime \prime} Q=\frac{\partial^{2} w}{\partial Q^{2}}$

Third partial derivative of deflection with respect to $\mathrm{R}$ and $\mathrm{Q}$ is: $W^{\prime \prime} R^{\prime} Q=\frac{\partial^{3} w}{\partial R^{2} \partial Q}$

$D=\frac{E t^{3}}{12\left(1-\mu^{2}\right)}$ is flexural rigidity, $\mathrm{t}$ is the plate thickness. $\mathrm{E}$ is Young's modulus.

\section{INTRODUCTION}

Since the origin of plate, Fourier and trigonometric series has been used to treat plate problems as shape function. There are many approaches many scholars employed in solving the problem of plates like energy method, numerical method, and equilibrium method. These approaches give approximate results in most difficult situations.

C.Erdem and Ismail used numerical method to analyze an isotropic rectangular plate with four clamped edges under distributed loads of an exact solution of the governing equation in terms of trigonometric and hyperbolic function[1]. They also compared the obtained results with those earlier reported, which shows reasonable agreement with other available results, but with a simpler and practical approach. Robert and Govindjee used the classical double cosine series expansion and an exploit of the ShermanWoodburg Formular to solve the problem of clamped rectangular plate [2]. Ibearugbulem used Taylor-Mclaurin's series as shape function to analyze the instability of axially compressed thin rectangular plate with four edges clamped [5]. He truncated the Taylor-Mclaurins series at the fifth term which satisfied all the boundary conditions of the plate. Upon substituting the resulted shape function into the total potential energy, he obtained the critical buckling load of the plate. Some scholars used finite element method in analyzing the problems of rectangular plate like Han and Petty[3], Tajdari et al [11], An- chien Wu et al [10], Ye [9], Rakesh [8], Sandeep Singh et al [7], and Ganapathi et al [4]

Although the buckling analysis of rectangular plates has received the attention of many researchers for several years, its treatment has left much to be done. Most of the available solutions do not satisfy exactly the prescribed boundary conditions or the governing differential agnation or both. In the past, there were no reference books to which 
Engineers and students can turn to for a clear and orderly exposition of the Isotropic rectangular plate with clamped clamped - free - clamped edge subjected to dynamic boundary conditions, which are also known as non-essential boundary condition. Ibearugbulemsolved CCFC rectangular plate using Taylor - Mclaurin's shape function with the aid of eigen value computer programme[6].

In order to provide the solutions to this problem, this paper is presented to address the issue. The plate is subjected to inplane load in one axis (x-axis) of the principal plane as shown in figure 1.

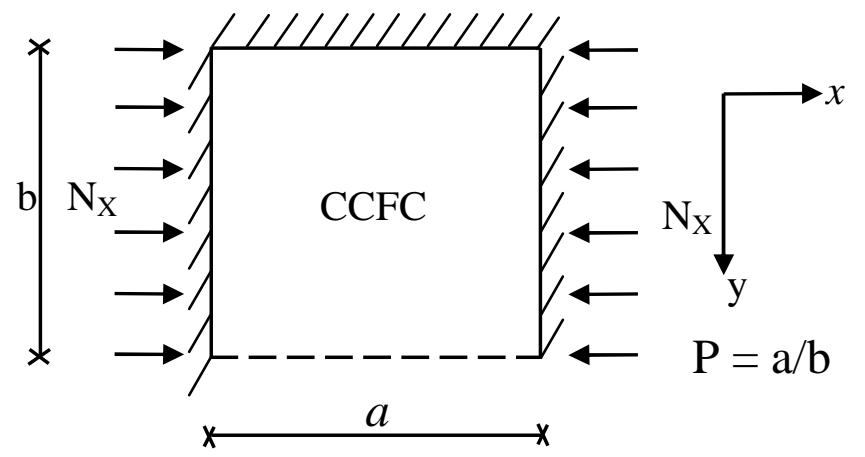

2. TOTAL POTENTIAL ENERGY FUNCTIONAL FOR BUCKLING OF PLATE.

Ibearugbulem [6] derived the total potential energy functional for a rectangular isotropic plate subjected to inplane load in $\mathrm{x}$ - direction and the polynomial shape function as follows;

$\pi_{\mathrm{x}}$

$\left.=\frac{\mathrm{D}}{2 \mathrm{~b}^{2}} \int_{0}^{1} \int_{0}^{1}\left[\frac{\mathrm{b}^{3}}{\mathrm{a}^{3}}\left(\mathrm{w}^{\prime \prime}\right)^{\mathrm{R}}\right)^{2}+\frac{\mathrm{a}}{\mathrm{b}}\left(\mathrm{w}^{\prime \prime} \mathrm{Q}\right)^{2}+\frac{2 \mathrm{~b}}{\mathrm{a}}\left(\mathrm{w}^{\prime \mathrm{R}^{\prime} \mathrm{Q}}\right)^{2}\right] \partial \mathrm{R} \partial \mathrm{Q}$

$-\frac{\mathrm{bN}_{\mathrm{x}}}{2 \mathrm{a}} \int_{0}^{1} \int_{0}^{1}\left(\mathrm{w}^{\prime \mathrm{R}}\right)^{2} \partial \mathrm{R} \partial \mathrm{Q}$

$W=\sum_{\mathrm{m}=0}^{4} \sum_{\mathrm{n}=0}^{4} \mathrm{a}_{\mathrm{m}} \mathrm{R}^{\mathrm{m}} \cdot \mathrm{b}_{\mathrm{n}} \mathrm{Q}^{\mathrm{n}}$

Where "a" and "b" are plate dimensions (lengths) along $\mathrm{x}$ and y directions. $\mathrm{Nx}$ is the in-plane load in $\mathrm{x}$-direction, $\mathrm{D}$ is flexural rigidity. $\mathrm{W}$ is the shape function. $\pi_{\mathrm{x}}$ is Total potential energy functional with load along $\mathrm{x}-$ axis; $\mathrm{R}=\frac{\mathrm{x}}{\mathrm{a}} ; \mathrm{Q}=$ $\frac{\mathrm{y}}{\mathrm{b}} ; 0 \leq \mathrm{R} \leq 1 ; 0 \leq \mathrm{Q} \leq 1 \quad(\mathrm{R}$ and $\mathrm{Q}$ are dimensionless quantities).

\section{SHAPE FUNCTION RESULTING FROM}

\section{POLYNOMIAL SERIES.}

The boundary conditions for CCFC plate are;

$$
\begin{aligned}
& \mathrm{w}_{(\mathrm{R}=0)}=0 ; \mathrm{w}_{(\mathrm{Q}=0)}=0 ; \mathrm{w}_{(\mathrm{R}=1)}=0 \\
& \mathrm{w}^{\prime \mathrm{R}}(\mathrm{R}=0)=0 ; \mathrm{w}^{\prime \mathrm{Q}}(\mathrm{Q}=0)=0 ; \mathrm{w}^{\prime \mathrm{R}}{ }_{(\mathrm{R}=1)}=0 \\
& \mathrm{~V}_{\mathrm{Q}_{(\mathrm{Q}=1)}}=\left[\mathrm{w}^{\prime \prime \mathrm{Q}}+(2-\mu) \mathrm{w}^{\prime \prime \mathrm{R}}{ }^{\prime \mathrm{Q}}\right]_{(\mathrm{Q}=1)}=0
\end{aligned}
$$

Applying these boundary conditions in equation 2 gave;

$\mathrm{w}=\mathrm{A}\left(\mathrm{R}^{2}-2 \mathrm{R}^{3}+\mathrm{R}^{4}\right)\left(4 \mathrm{Q}^{2}-4 \mathrm{Q}^{3}+\mathrm{Q}^{4}\right)$

\section{APPLICATION OF RITZ METHOD}

Partial derivative of equation (6) with respect to either R or $\mathrm{Q}$ or both gave the following equations;

$$
\begin{aligned}
& \mathrm{w}^{\prime \mathrm{R}}=\mathrm{A}\left(2 \mathrm{R}-6 \mathrm{R}^{2}+4 \mathrm{R}^{3}\right)\left(4 \mathrm{Q}^{2}-4 \mathrm{Q}^{3}+\mathrm{Q}^{4}\right) \\
& \mathrm{w}^{\prime \prime \mathrm{R}}=\mathrm{A}\left(2-12 \mathrm{R}+12 \mathrm{R}^{2}\right)\left(4 \mathrm{Q}^{2}-4 \mathrm{Q}^{3}+\mathrm{Q}^{4}\right) \\
& \mathrm{w}^{\prime \mathrm{Q}}=\mathrm{A}\left(\mathrm{R}^{2}-2 \mathrm{R}^{3}+\mathrm{R}^{4}\right)\left(8 \mathrm{Q}-12 \mathrm{Q}^{2}+4 \mathrm{Q}^{3}\right) \\
& \mathrm{w}^{\prime \prime \mathrm{Q}}=\mathrm{A}\left(\mathrm{R}^{2}-2 \mathrm{R}^{3}+\mathrm{R}^{4}\right)\left(8-24 \mathrm{Q}+12 \mathrm{Q}^{2}\right) \\
& \mathrm{w}^{\prime \mathrm{R}} \mathrm{Q}=\mathrm{A}\left(2 \mathrm{R}-6 \mathrm{R}^{2}+4 \mathrm{R}^{3}\right)\left(8 \mathrm{Q}-12 \mathrm{Q}^{2}+4 \mathrm{Q}^{3}\right)
\end{aligned}
$$

Integrating the square of these equations (7), (8), (10), and (11) partially with respect to $\mathrm{R}$ and $\mathrm{Q}$ in a closed domain respectively gave:

$$
\begin{aligned}
& \int_{0}^{1} \int_{0}^{1}\left(w^{\prime R}\right)^{2} \partial R \partial Q \\
& =A^{2}(0.019047619)(0.406349206)=0.007739984876 A^{2}
\end{aligned}
$$$$
\int_{0}^{1} \int_{0}^{1}\left(\mathrm{w}^{\prime \prime \mathrm{R}}\right)^{2} \partial \mathrm{R} \partial \mathrm{Q}
$$$$
=\mathrm{A}^{2}(0.8)(0.40634920)=0.325079365 \mathrm{~A}^{2}
$$$$
\int_{0}^{1} \int_{0}^{1}\left(\mathrm{w}^{\prime \prime \mathrm{Q}}\right)^{2} \partial \mathrm{R} \partial \mathrm{Q}
$$$$
=\mathrm{A}^{2}\left(1.587301587 \times 10^{-3}\right)(12.8)=0.02031746 \mathrm{~A}^{2}
$$

$$
\begin{aligned}
& \int_{0}^{1} \int_{0}^{1}\left(\mathrm{w}^{\prime \mathrm{R} / \mathrm{Q}}\right)^{2} \partial \mathrm{R} \partial \mathrm{Q} \\
& =\mathrm{A}^{2}(0.019047619)(1.219047619)=0.023219954 \mathrm{~A}^{2}
\end{aligned}
$$

Substituting equations (12), (13), (14) and (15) into equation (1), and minimizing it gave the following result;

$\frac{\pi \mathrm{x}}{\partial \mathrm{A}}=\frac{\mathrm{DA}^{2}}{\mathrm{~Pa}^{2}}\left(0.325079365+0.02031746 \mathrm{P}^{4}\right.$
$\left.+0.023219954 \mathrm{P}^{2}\right)$

$-\frac{\mathrm{N}_{\mathrm{x}} \mathrm{A}^{2}}{2 \mathrm{P}}(0.007739984876)=0$

Making $\mathrm{N}_{\mathrm{X}}$ the subject of the equation (16) with aspect ratio of $\mathrm{P}=\mathrm{a} / \mathrm{b}$

$\mathrm{N}_{\mathrm{x}}=$

$$
\begin{array}{r}
\frac{\mathrm{D} \pi^{2}}{\mathrm{~b}^{2}}\left(\frac{4.255489716}{\mathrm{P}^{2}}+0.265968103 \mathrm{P}^{2}\right. \\
+0.303963542)(17)
\end{array}
$$

\section{RESULT AND CONCLUSIONS}

A graph of critical buckling load against aspect ratio was plotted. From the graph, it was observed that as the aspect ratio increases from 0.1 to 2.0 , the critical buckling load decreases. The graph was divided into two segments ranging from 0.1 to 0.7 In the first segment, the graph is of 6 th degree polynomial with an equation of $\mathrm{Y}=21892 \mathrm{X}^{6}-$ $60455 X^{5}+68130 X^{4}-40190 X^{3}+13164 X^{2}-23034 X+$ 
1752. In the second segment, the graph is of 5th degree polynomial with an equation of $\mathrm{Y}=-5.704 \mathrm{X}^{5}+44.58 \mathrm{X}^{4}$ $139.9 X^{3}+223.4 X^{2}-184.7 X+67.20$.

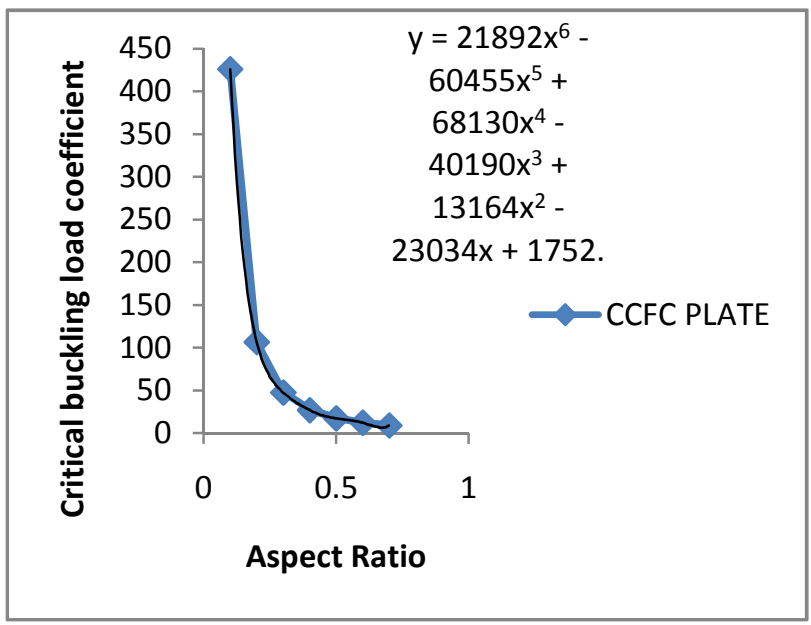

a: First Segment

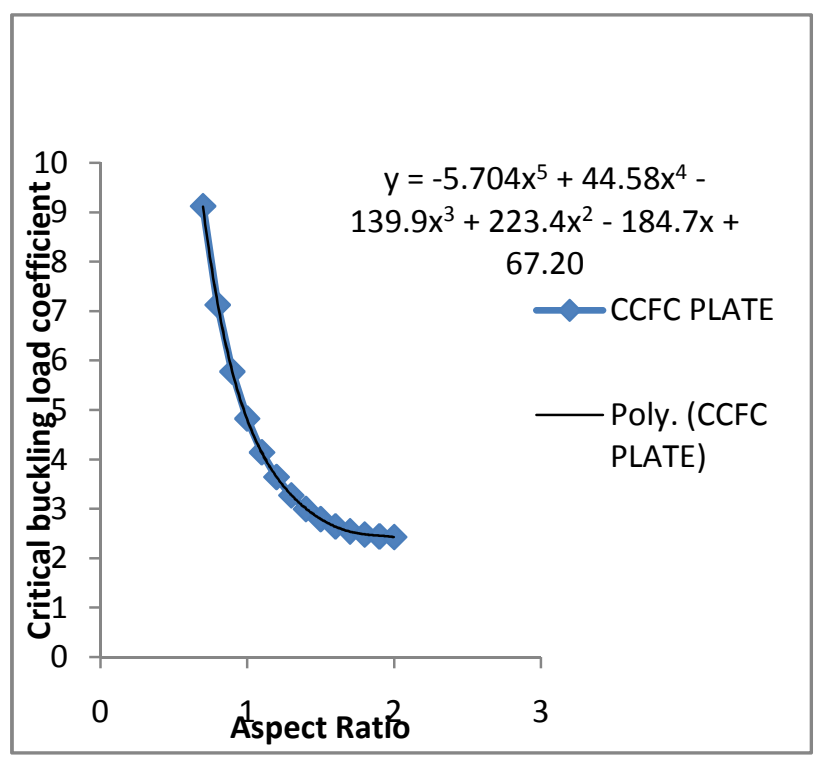

b: Second Segment

Figure 2: Graph of critical buckling load against aspect ratio.

The average percentage difference between the solutions from Ibearugbulem and the present study shown on table 1 was $32.112 \%$. This value is more than the required percentage because Ibearugbulem used a rigorous computer matrix program to analyze the plate which has so many disadvantages. It was observed that as the aspect ratio increases from 0.1 to 2.0 , the present work and Ibearugbulem start converging.
Table 1: $\mathrm{K}$ values for different aspect ratios for CCFC rectangular plate

\begin{tabular}{|l|l|l|l|l|}
\hline $\begin{array}{c}\text { Aspect } \\
\text { Ratio }\end{array}$ & $\begin{array}{c}\text { Z From } \\
\text { Ibearugbul } \\
\text { em (2012) }\end{array}$ & $\begin{array}{c}\text { Z From } \\
\text { Present } \\
\text { Study }\end{array}$ & $\begin{array}{c}\text { Differe } \\
\text { nces }\end{array}$ & $\begin{array}{l}\text { Percentage } \\
\text { Difference }\end{array}$ \\
\hline 0.1 & 159.16 & 425.86 & 266.69 & 167.56 \\
\hline 0.2 & 54.24 & 106.70 & 52.42 & 96.72 \\
\hline 0.3 & 35.41 & 47.61 & 12.20 & 34.46 \\
\hline 0.4 & 27.29 & 26.94 & 0.35 & 1.27 \\
\hline 0.5 & 17.73 & 17.39 & 0.34 & 1.90 \\
\hline 0.6 & 12.54 & 12.22 & 0.32 & 2.55 \\
\hline 0.7 & 9.42 & 9.12 & 0.30 & 3.20 \\
\hline 0.8 & 7.41 & 7.12 & 0.29 & 3.88 \\
\hline 0.9 & 6.05 & 5.77 & 0.28 & 4.58 \\
\hline 1 & 5.08 & 4.83 & 0.25 & 5.01 \\
\hline
\end{tabular}

\section{CONCLUSION}

The polynomial series as a shape function was applied in this paper for the buckling behavior of an isotropic rectangular plate.It was also deduced that the polynomial series satisfies all the non-essential (Dynamics) boundary conditions of the graph.

The shape function derived in this approach is a good alternative to the shape function assumed using trigonometric series. Therefore, the present method can accurately predict the critical buckling load of isotropic rectangular plates.

\section{REFERENCE}

[1]. C. ErdemImrak and Ismail Gerdemeli (2006), "The problem of isotropic rectangular plate with four clamped edge". Journal of Sadhana, vol. 32, Part 3, Pp 181-186.

[2]. Robert L.Taylor and Sanjay Govindjee (2002),"Solution of Clamped Rectangular Plate Problem". Journal of Structural Engineering Mechanic and Materials. Vol.9.

[3]. Han, W.,Petyt, M.(1997)."Geometrically Nonlinear Vibration Analysis of Thin Rectangular Plates Using the Hierarchical Finite Element Method". 
Journals of Computers \& Structures, vol. 63, issue 2, Pp 295 - 308.

[4]. Ganapathi, M., Varadan, T.K, and Sharma, B.S (1991)." Nonlinear Flexural Vibration of Laminated Orthotropic Plate". Journal of Computers and Structures. Vol. 39, Issue 6, Pp 685 -688 .

[5]. Ibearugbulem, O.M, Osadebe, N.N., Ezeh, J.C., Onwuka, D. O (2013). "Instability of Axially Compressed CCCC Thin Rectangular Plate Using Taylor-Mclaurins Series Shape Function on Ritz Method". Journal of Academic Research International, vol. 4, No. 1., Pp 346-351

[6]. Ibearugbulem, O.M. (2012). "Application of a Direct Variational Principal in Elastic Stability of Rectangular Flat Thin Plates". Ph.D. Thesis submitted to postgraduate school, Federal University of Technology, Owerri, Nigeria.

[7]. Sandeep Singh et al (2012). "Buckling Analysis of Thin Rectangular Plates with Cutouts Subjected to Partial edge Compression Using FEM". Journal of Engineering, Design and Technology, vol.10, issue1.

[8]. Rakesh TimappaNaik (2010)."Elastic Buckling Studies of Thin Plates and Cold-Formed Steel Members in Shear". Report Submitted to the Faculty of Virginia Polytechnic Institute and State University in Partial Fulfillment of the Requirements for the Degree of Master of Science in Civil Engineering.

[9]. Ye Jianqiao (1994). "Large Deflection of Imperfect Plates by Iterative BE-FE Method". Journal of Engineering Mechanics, vol. 120, No. 3,Pp 431445.

[10]. An-Chien Wu, Pao-Chun Lin and Keg-Chyuan Tsai (2013), "High-Mode Buckling-Restrained Brace Core Plate",Journals of the International Association for Earthquake Engineering.

[11]. Tajdari, M., Nezamabadi, A.R., Naeemi, M and Pirali, P (2011), "The Effects of Plate-Support Condition on Buckling Strength of Rectangular Perforated Plates under Linearly Varying in-plane Normal Load", Journal of World Academy of Science, Engineering and Technology, vol. 54, Pp 479-486. 